\title{
Continuous murmur in pulmonary atresia with reference to aortography
}

\author{
W. Zutter ${ }^{1}$ and Jane Somerville \\ From the Institute of Cardiology and National Heart Hospital, London W.I
}

The site and variation of a continuous murmur and its correlation to the anatomy of aortopulmonary communications were studied in 32 patients with pulmonary atresia and large ventricular septal defect.

A continuous murmur localized beneath the left clavicle was always associated with a persistent duct. When a continuous murmur beneath the left clavicle and at another site was heard in the absence of transposition, large collateral arteries but not a duct were the cause. A continuous murmur in the right upper chest was always associated with a right aortic arch and large collateral arteries perfusing the right upper lobe.

It is shown that clinical examination in pulmonary atresia gives additional information about the anatomy of the aortopulmonary communications, which helps in planning catheterization and angiocardiography.

A continuous murmur is commonly present in patients with pulmonary atresia associated with a large ventricular septal defect. Sometimes it is caused by a persistent ductus arteriosus (Nadas, 1963; Tynan and Gleeson, 1966), but there are other forms of aortopulmonary communication which may cause this physical sign. The purpose of this paper is to examine the relation between the presence, site, and variation of the continuous murmur and the anatomy of aortopulmonary communications in pulmonary atresia.

\section{Materials and method}

A total of thirty-two patients with pulmonary atresia and large ventricular septal defect aged from 6 months to 15 years, who were referred for consideration of surgical treatment to the National Heart Hospital, was studied. Patients with a functioning surgical shunt at the time of study were excluded.

The diagnosis of pulmonary atresia with large ventricular septal defect was confirmed in every case by right ventricular angiocardiography. In addition, ascending aortography which provided information about the aortopulmonary communications and a long angiocardiographic covertime was used to ensure the clear delineation of pulmonary arteries, if present (Somerville, 1969). When it was evident that there were large systemic arteries arising from the descending aorta, selective injections were made into the descending

Received 3 February 1971.

1 Supported by a grant from the Royal Society and the Swiss National Fund. aorta and into aberrant vessels so that their anatomy and course could be studied (Rees and Somerville, 1969; Chesler, Beck, and Schrire, 1970).

Auscultation in each patient was performed over the back and front of the chest and the presence or absence and the site of maximal intensity of a continuous murmur were noted. These findings were then correlated with the aortographic demonstration of aortopulmonary communications such as a persistent duct, large systemic collateral arteries, and the presence of stenosis in these arteries.

\section{Results}

Five patients had no audible continuous murmur in any part of the chest; 4 of these had multiple small collateral vessels and I had large collaterals from the descending aorta (Fig. I).

Twenty-seven patients had a continuous murmur which was easily heard and increased on inspiration. The site of the continuous murmur with the corresponding number of patients is correlated with the anatomy of the aortopulmonary communications in the Table.

In 12 patients the continuous murmur was maximal beneath the left clavicle and all of this group had a demonstrable patent duct supplying one or both pulmonary arteries. Only I of these patients had large collaterals to the left and right upper lobe from the descending aorta (Fig. 2), which were clinically silent. As seen from the Table, the collaterals in the other II patients were either 


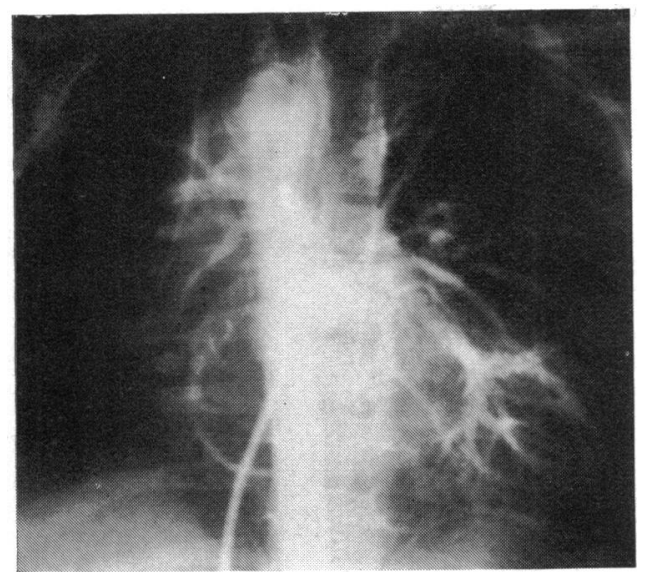

FI G. I Aortogram showing large collaterals arising from the descending aorta, which were clinically silent.

very small and numerous or absent and the duct was the sole important supply to the lungs.

A further 5 patients with a loud continuous murmur under the left clavicle had an additional murmur at another site. This additional murmur was localized posteriorly over the left or right lower lobe area in 4 and did not appear to radiate from the subclavicular region. In these patients there was a large collateral artery arising from the descending aorta supplying the lobe of the lung in the area of the murmur. There was an obvious stenosis near the origin of the collateral in 2 (Fig. 3) and the other 2 had no obvious stenosis (Fig. 4). One further patient with a loud continuous murmur under both clavicles had only a left-sided duct but his pulmonary atresia was associated with corrected transposition of the great arteries.

In the remaining Io patients a continuous murmur was maximal in one or more other sites than beneath the left clavicle. In 5, the murmur was loudest over the right upper chest and all had a right-sided aortic arch. One of these 5 had a large single collateral from the descending aorta which supplied both lungs with blood; this large artery turned acutely in the right chest (Fig. 5) which may have caused increased turbulence. Another patient had an unusually large right internal mammary artery branching into pulmonary vessels and looking like a natural Blalock anastomosis (Fig. 6) and in addition had a stenosed collateral artery supplying the right upper lobe, as did one other patient (Fig. 7) in whom the murmur was very loud over the apex of the right lung. Another patient with

TABLE Relation of site of continuous murmur to anatomy of aortopulmonary communications in pulmonary atresia

\begin{tabular}{|c|c|c|c|c|c|c|}
\hline \multirow{2}{*}{$\begin{array}{l}\text { Site of continuous } \\
\text { murmur }\end{array}$} & \multirow{2}{*}{$\begin{array}{l}\text { No. of } \\
\text { patients }\end{array}$} & \multicolumn{5}{|c|}{ Anatomy of aortopulmonary communications } \\
\hline & & Duct & $\begin{array}{l}\text { No } \\
\text { duct }\end{array}$ & $\begin{array}{l}\text { Large } \\
\text { collateral } \\
\text { and } \\
\text { stenosis }\end{array}$ & $\begin{array}{l}\text { Large } \\
\text { collateral } \\
\text { and no } \\
\text { stenosis }\end{array}$ & $\begin{array}{l}\text { Small and } \\
\text { spidery } \\
\text { collaterals }\end{array}$ \\
\hline $\begin{array}{l}\text { No continuous } \\
\text { murmur }\end{array}$ & 5 & - & 一 & - & $\mathbf{I}$ & 4 \\
\hline $\begin{array}{l}\text { Only left sub- } \\
\text { clavicular area }\end{array}$ & 12 & 12 & - & - & $\mathbf{I}$ & $\begin{array}{c}\text { I I small o } \\
\text { absent }\end{array}$ \\
\hline $\begin{array}{l}\text { Left sub-clavicular } \\
\text { area + other site }\end{array}$ & 5 & $\begin{array}{l}\text { I } \\
+ \text { TGA }\end{array}$ & 4 & 2 & 2 & I \\
\hline $\begin{array}{l}\text { Other sites (than } \\
\text { sub-clavicular) }\end{array}$ & IO & - & 10 & 4 & 5 & I \\
\hline
\end{tabular}

$T G A=$ Transposition of the great arteries.

FIG. 2 Selective injections of large arteries arising from the descending aorta and perfusing the right upper lobe, the left upper lobe, and lingula; there was no continuous murmur over these areas.
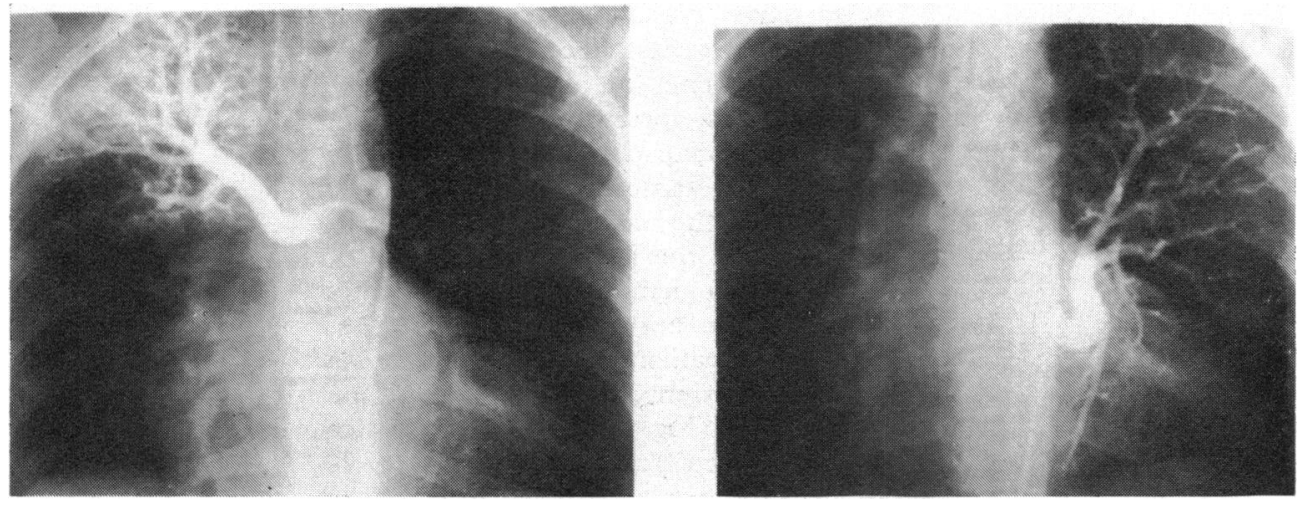


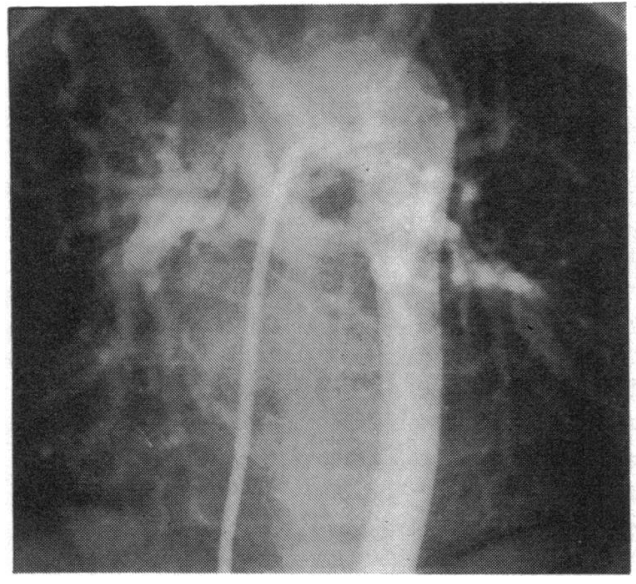

FI . 3 Aortic injection showing a stenosis of a collateral artery arising from the descending aorta. A continuous murmur was heard over the right upper lobe area.

transposition had a single large collateral entering the hilar pulmonary arteries and the fifth patient with a right-sided continuous murmur had only small collaterals carrying little blood flow to the right lung.

In a further 3 of the remaining ro patients the continuous murmur was heard only posteriorly over the left chest and all had large collateral arteries from the descending aorta

FIG. 4 Aortogram from a patient with a soft continuous murmur over the right chest only. $A$ right aortic arch is present and the collateral arteries are few and not tortuous or stenosed.

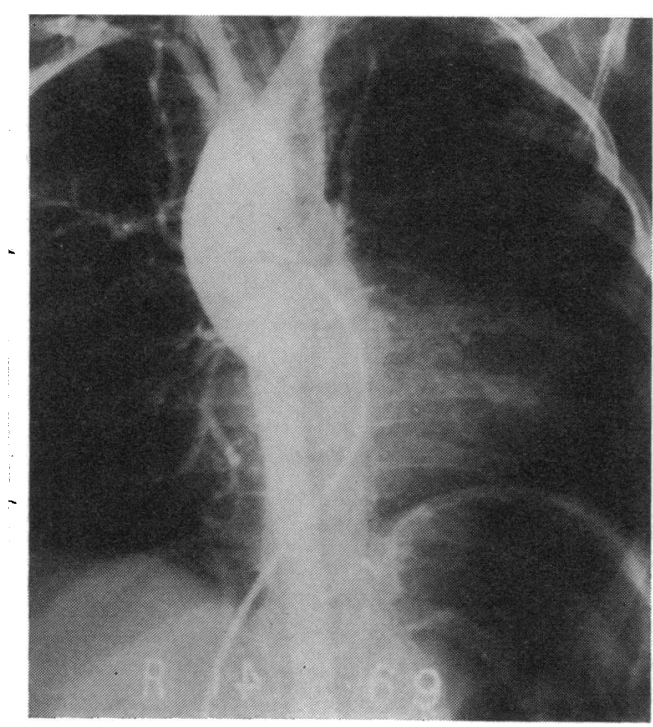

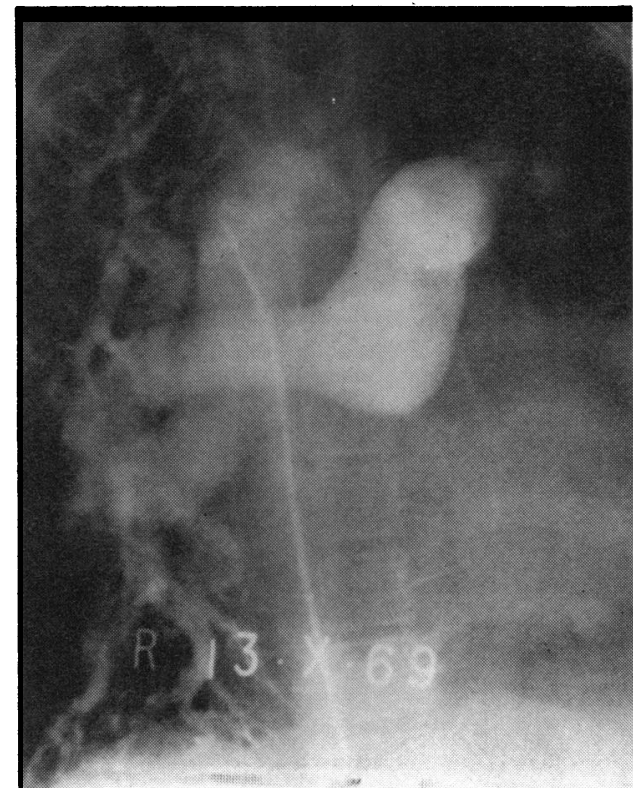

FIG. 5 Aortogram showing a large single collateral from the descending aorta which perfuses the right lung and, after turning acutely in the right chest, crosses the hilum to supply the left lung with blood. A continuous murmur was heard over the right upper chest but not in the left chest.

FI G. 6 Aortogram showing a very large right internal mammary artery branching into pulmonary vessels and looking like a natural Blalock anastomosis. A continuous murmur was heard over the right upper chest.

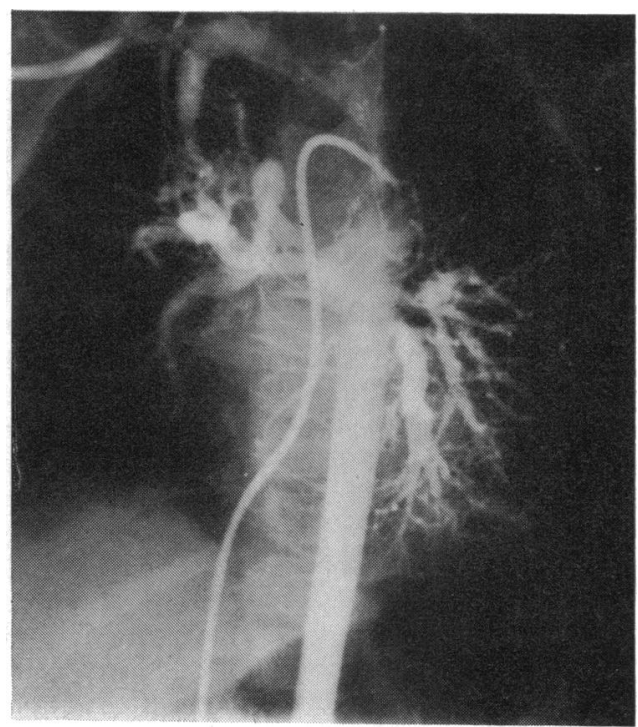




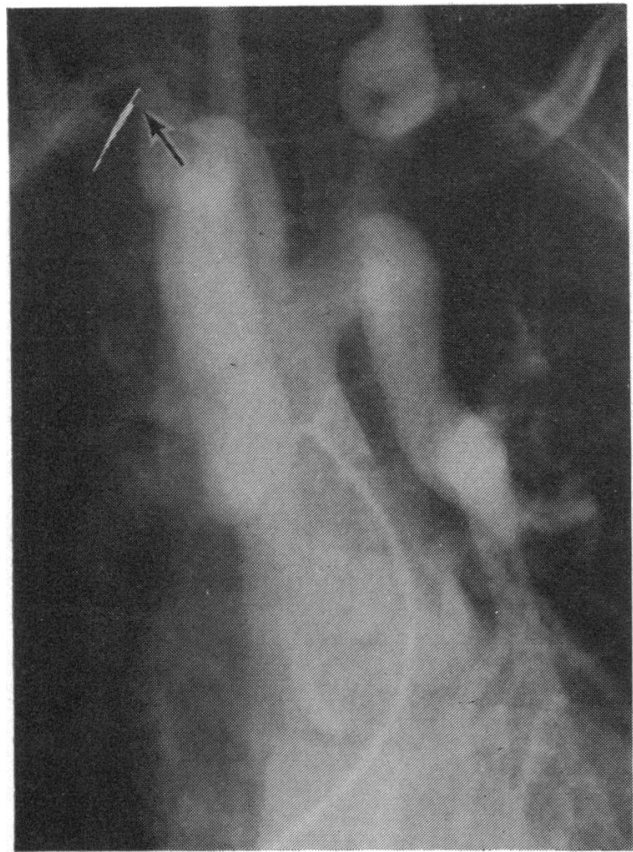

FI G. 7 Aortogram showing a conspicuous stenosis of a large collateral artery supplying the right upper lobe. A continuous murmur was heard over the right upper chest. No murmur was heard over the left chest despite the unusual blood supply to the left lung.

FI 8 Aortogram showing a large collateral artery arising from the left and turning in the left chest to cross the midline to supply the right lung. A loud continuous murmur was localized over the midposterior zone on the left.

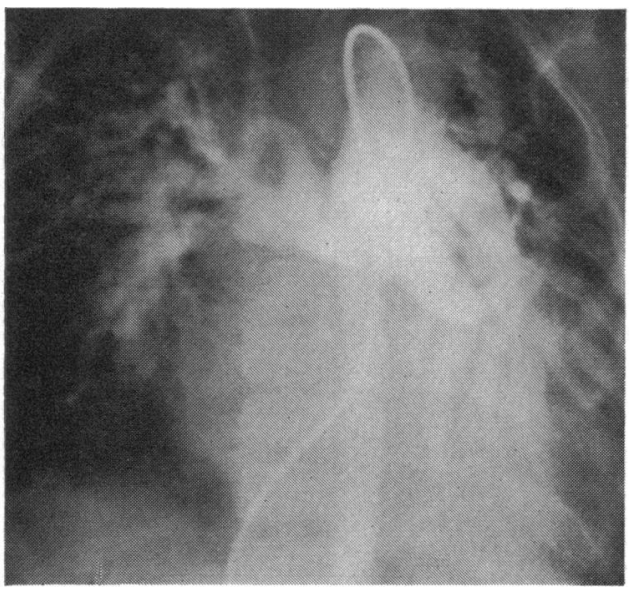

supplying the lower lobes, but only I had a narrowing along its course. Another one had a large collateral arising from the left and turning in the left chest to cross the midline to supply the right lung (Fig. 8). Two other patients with continuous murmur over both lungs posteriorly had bilateral large collateral arteries from the descending aorta to both lungs.

\section{Discussion}

The types of aortopulmonary communication upon which a patient with pulmonary atresia and ventricular septal defect depends are variable, and the anatomy of these influences both investigation and surgical treatment (Ongley et al., 1966).

Study of the site and presence of continuous murmurs has given useful information about these vital connexions which may be a simple duct, multiple spidery bronchial arteries, or single or several bizarre systemic collateral arteries (Jefferson, Rees, and Somerville, 1972).

A continuous murmur under the left clavicle was present in 13 of 32 patients and was always associated with a persistent duct. When the murmur was heard beneath the left clavicle and at another site as in only 4, there were large collateral arteries perfusing that part of the lung beneath the murmur and no duct was found. The one exception was in transposition with duct where the murmur was well heard over both sides of the upper chest and it was assumed that the unusual lie of the pulmonary arteries may have accounted for the excellent conduction of the murmur towards the right.

In 5 patients with a continuous murmur under the right clavicle there was always a right aortic arch with complex arterial supply to the lung in 4. They had one or more large collateral arteries arising from below the isthmus to perfuse the right upper lobe, and in 2 cases they were stenosed either at the origin or at an upward kink at the level of the hilum.

In 5 patients with a continuous murmur maximal at sites other than beneath the left clavicle, there was usually a large collateral artery arising from the descending aorta and a duct was never found. In 2 with loudest murmur there was a stenosis of the collateral before joining with hilar pulmonary vessels.

The finding of a continuous murmur posteriorly in pulmonary atresia thus suggested a complex blood supply to the lungs, and selective aortography from below through femoral puncture or arteriotomy was done initially on these patients (Somerville, I970) instead of the usual routine ascending aortogram 
(Lamers and Bruins, 1958) which obscured the origin of these arteries arising from the descending aorta. Prior knowledge of the presence of these collaterals from clinical examination can save additional investigation if selective angiography was done at the first study.

Only 2 of the 15 patients who had large collaterals did not have a continuous murmur to suggest the presence of these abnormal arteries. Neither had a stenosis in the collateral, and it is possible that both had severe pulmonary vascular disease in the lobes supplied by collaterals so that blood flow was low and there was no turbulence to produce a murmur. Histology of the lung supplied by the collateral showed severe pulmonary arteriolar thickening, suggesting advanced pulmonary vascular disease.

In 4 of the 5 patients without a continuous murmur in any part of the chest, there was no duct or large collateral arteries, and the pulmonary circulation was dependent on many fine bronchial arteries arising from the aorta and its branches. These patients were very cyanosed with a very poor pulmonary blood flow but always had good central pulmonary artery development. So the patient with pulmonary atresia without a continuous murmur usually ultimately had a surprisingly good surgical prognosis whereas those with loud murmurs to the right or posteriorly often had large collaterals with incomplete pulmonary artery development and tended to present difficult surgical problems.

The loudest continuous murmurs were found in patients with either a good sized but funnelled duct and those with large collateral arteries with a single stenosis or carrying a large blood flow through a tortuous course. In contrast, faint murmurs arose from small, relatively ineffective, collateral arteries.

It is concluded that in patients with pulmonary atresia, auscultation over the whole chest anteriorly and posteriorly with assessment of the site of maximal intensity gives useful information on the systemic supply to the lungs. When the pulmonary blood flow is very poor or if there is severe pulmonary vascular disease, no murmur may be heard. A continuous murmur, if present, can originate from a duct, from large collaterals with or without a stenosis, and occasionally from multiple small collaterals. Knowledge about the anatomy from clinical examination helps in planning the catheterization and angiocardiography and ultimate management.

\section{References}

Chesler, E., Beck, W., and Schrire, V. (1970). Selective catheterization of pulmonary or bronchial arteries in the preoperative assessment of pseudotruncus arteriosus and truncus arteriosus type IV. American fournal of Cardiology, 26, 20.

Jefferson, K., Rees, S., and Somerville, J. (I972). Systemic arterial supply to the lungs in pulmonary atresia and its relation to pulmonary artery development. British Heart fournal. In the press.

Lamers, J. J. H., and Bruins, C. (1958). Thoracic aortography in atresia of the pulmonary artery. Archivum Chirurgicum Neerlandicum, 10, 386.

Nadas, A. S. (1963). Pulmonic atresia with intact ventricular septum. In Pediatric Cardiology, 2nd ed., p. 6r4. W. B. Saunders, Philadelphia and London.

Ongley, P. A., Rahimtoola, S. H., Kincaid, O. W., and Kirklin, J. W. (I966). Continuous murmurs in tetralogy of Fallot and pulmonary atresia with ventricular septal defect. American fournal of Cardiology, 18, $82 \mathrm{I}$.

Rees, S., and Somerville, J. (1969). Aortography in Fallot's tetralogy and variants. British Heart fournal, 31, 146.

Somerville, J. (1969). Angiocardiography in pulmonary atresia. In Proceedings of the Association of European Paediatric Cardiology, Vol. 5, p. 32.

Somerville, J. (1970). Management of pulmonary atresia. British Heart fournal, 32, 641.

Tynan, M. J., and Gleeson, J. A. (1966). Pulmonary atresia with bronchial arteries arising from the subclavian arteries. British Heart fournal, 28, 573.

Requests for reprints to Dr. Jane Somerville, Institute of Cardiology, 35 Wimpole Street, London WI M8EX. 